\title{
A Landslide Monitoring System for Transmission Lines Corridor
}

\author{
Qinghua $\mathrm{Lu}^{1,2, a}$, Changhua Zhang ${ }^{1,2, b}$, Wenlong Yang ${ }^{1,2}$, Chen Jiang ${ }^{1,2}$ \\ ${ }^{1}$ Energy Science and Engineering School, University of Electronic Science and Technology of China, \\ Chengdu 611731, China \\ ${ }^{2}$ Institute of Smart Grid \& Advanced Measurement Technology, UESTC, Chengdu 611731, China \\ aluqinghualu@163.com, bzhangchanghua@uestc.edu.cn
}

Keywords: landslide, transmission corridor, on-line monitoring, Zigbee, wireless sensor network.

\begin{abstract}
Landslide is a common kind of geologic hazards, which is a very serious potential threat for security operation of power system. Therefore it is valuable to research and develop a landslide online monitoring system to monitor landslide which lies very close to power tower. Based on current research, in this paper, wireless sensor network (WSN) technology is taken to build a monitoring network. Through it, some key information about landslide surface-crack width, internal layer sliding strain, sliding mass dip angle and groundwater level are measured and remotely transmitted to monitor center. Software deals with these data. And Verhulst model is applied to predict the possible time of an impending landslide, while posterior error estimator method is used to evaluate prediction accuracy. This monitoring system was installed near NO. 50 power tower of $500 \mathrm{kV}$ transmission Line in Mao County, Sichuan, China. Large amounts of data were obtained. Analysis results have proved its effectiveness.
\end{abstract}

\section{Introduction}

The area of southwest China is very important hydropower output corridor. However, it is also the high incidence area of natural disasters, such as landslides, earthquakes and so on. The mountain is prone to landslide induced by external factor, and that is the greatest threat to the safe operation of the grid.

In the power industry, technology about landslides and other geological disasters has been the concern of many researchers. Paper [1] applied satellite remote sensing and geographic information system technology in the project of "Danba Kangding 500kV Double Circuit Transmission Line". Paper [2] introduced power monitoring requirements on landslide from the perspective of smart grid construction. Definition of dangerous level of landslide is proposed. Overall, Research about landslide hazard by the power sector is not very prominent. Risk assessment of power systems, monitoring technology and prediction model are still in the exploratory stage.

Domestic and foreign scholars have begun more in-depth studies in the field of geological disasters. Optical fiber sensing technology, wireless sensor network technology (WSN: Wireless Sensor Network), networking technology and satellite remote sensing technology have been applied to explore in the field of landslide monitoring [3,4,5,6]. Paper [4] proposed a landslide monitoring system based on WSN and developed the device .It also designed an experiment to verify the prospect of WSN technology in the field of geological disasters research. For prediction of landslides time, Verhulst model is better than others model in the short-term and temporary slip forecasting model.

Based on existing research and combined with the landslide monitoring application requirements of the project of No. 50 power tower of Sichuan Maotan II transmission line, overall program of transmission corridor landslide online monitoring based on wireless sensor network (WSN) and key technologies are described in detail. 


\section{Constitution of Landslide Monitoring System}

As shown in figure 1, the monitoring system consists of hardware part and monitoring center software. Hardware part, composed of terminal node and coordinator node, is mainly to complete the information's collection, storage and transmission. The terminal node, which is composed of high precision sensor and ZigBee End Device, is mainly to collect the information of landslide, such as the landslide displacement, surface crack, underground water level and rainfall information. And the coordinator node is composed of ZigBee Coordinator, TI low-power microcontroller 430, solar power system and GPRS DTU (Service Data Transfer Unit), etc. Sensors include landslide displacement sensors, surface crack sensors, piezometer sensor, rain gauge and so on. The terminal node's power is supplied by low resistance lithium battery. The coordinator node's power is supplied by the solar power system. Solar power system consists of solar battery, waterproof controller and silicon accumulator. The terminal node collects data of sensors and transfer them to ZigBee Coordinator through the wireless sensor network. Then microcontroller (MCU: Micro Control Unit) stores the data into the flash memory and sents the data to the monitoring center through GPRS DTU finally.

According to the monitoring data obtained, Monitoring center can determine the condition of the landslide transmission corridor. Monitoring center also can set GPRS sender remote online (such as sending time interval, real time data acquisition interval, request, etc.). The monitoring center software visually display the displacement of landslide, surface crack, underground water level and rainfall information, and forecast the landslide displacement through the Verhulst model. If the landslide is in danger, the monitoring center software will send alarm information automatically so that the scheduling department can take measures to reduce the economic losses caused by landslide.

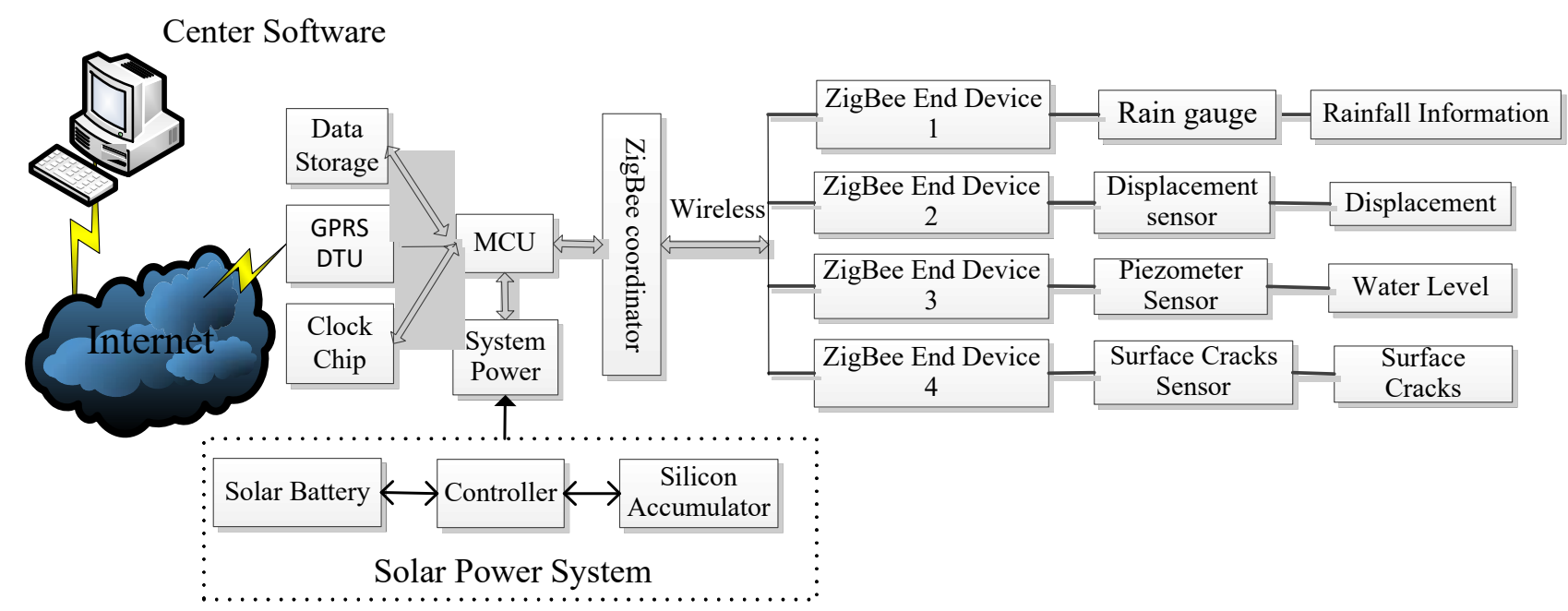

Fig. 1 Schematic of monitoring system

\section{Sensor Selection and Engineering Applications}

Transmission corridor landslide monitoring system is installed in the transmission corridor tower and will work in the field for a long time. So the system require low power consumption, high reliability, accuracy and free of maintenance operation.

Select HWY-1 displacement sensors to monitor the different depths' displacement in landslide. The sensors are divided into four groups to monitor $4 \mathrm{~m}, 6 \mathrm{~m}, 10 \mathrm{~m}$ and $16 \mathrm{~m}$ depth of the landslide displacement. Select LT-M-S(P) linear surface crack sensors to monitor the surface crack of the slide mass.

The landslide area is located near No. 50 power tower of Sichuan Maotan II transmission line. In addition to the displacement and surface crack, monitoring the other predisposing factors could provide decision support information for landslide prediction, such as dip angle, piezometer and so on. 


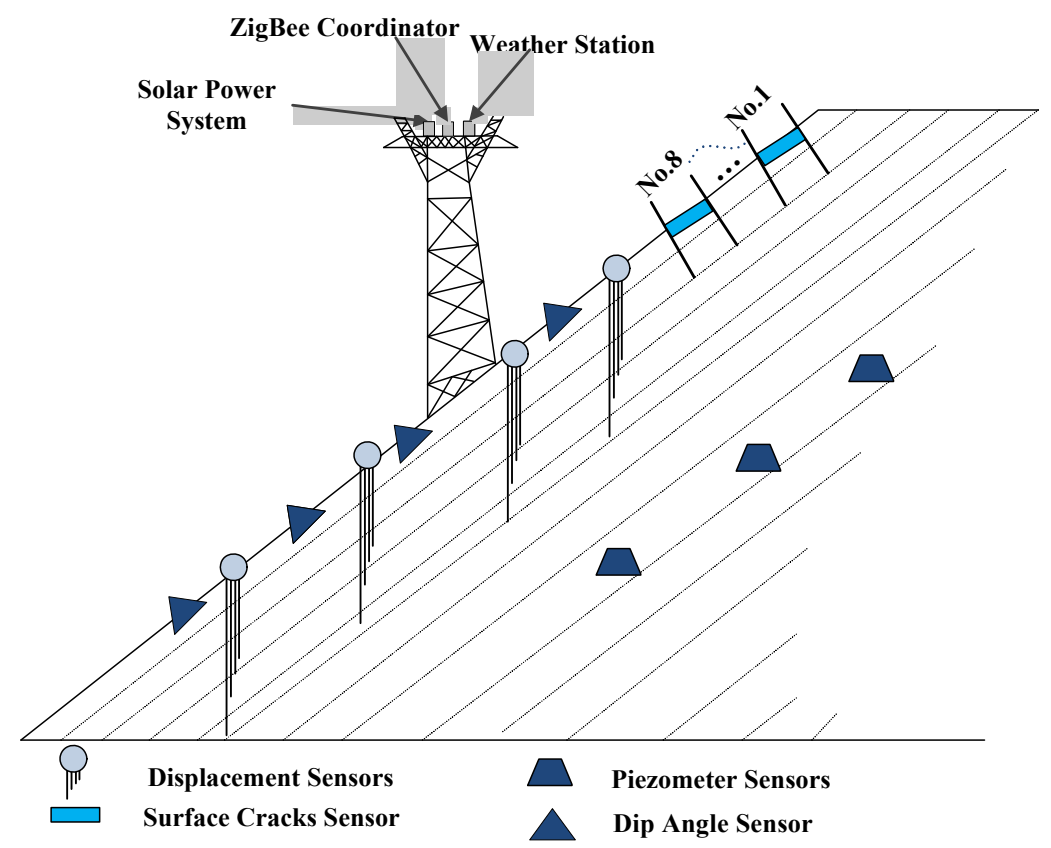

Fig. 2 Location of sensors and devices

\section{Analysis of Operating Result}

Landslide Prediction Models and Prediction Accuracy Test. The basic point of Verhulst landslide predictive model is that landslide evolution is an ongoing process of development, maturation and destruction [7]. Therefore, using non-linear gray Verhulst model can predict landslide displacement and temporary slip time. Displacement data of each group were processed by Verhulst model, so that the pro-slip time of each group can be predicted. Among them, the minimum time is the sliding time that landslides may occur.

Prediction accuracy assessment is an important part of prediction problem. The most probable methods include testing the prediction accuracy of the relative error inspection, grey correlative degree analysis and posterior error estimator. In this paper, we take the posterior error estimator to analyze the result.

The accuracy of the predicted value is determined according to posterior error estimator $\mathrm{C}$. The smaller the $\mathrm{C}$ value is, the better the result will be[7,8].

The Results and Analysis of Displacement Prediction. Use the observational data of 17, 18 and 19 weeks and Verhulst model to predict displacement curves of slide mass. The predicted value and the actual value of the third set of displacement sensor (at 10m depth) are shown in Figure 5. As can be seen from Figure 5: (1) The value of surface displacement has been growing over time, and the average daily displacements are much smaller than $10 \mathrm{~mm}$. It indicates that the landslide is still in the first stage. The prediction trends are based on monitoring data of 17 to 19 weeks and measured curve fit better. (3) The measured value is slightly larger or smaller than the predicted value, and as time increases, the measured and predicted values of the larger deviation. This is consistent with the general rules of forecasting problems. 


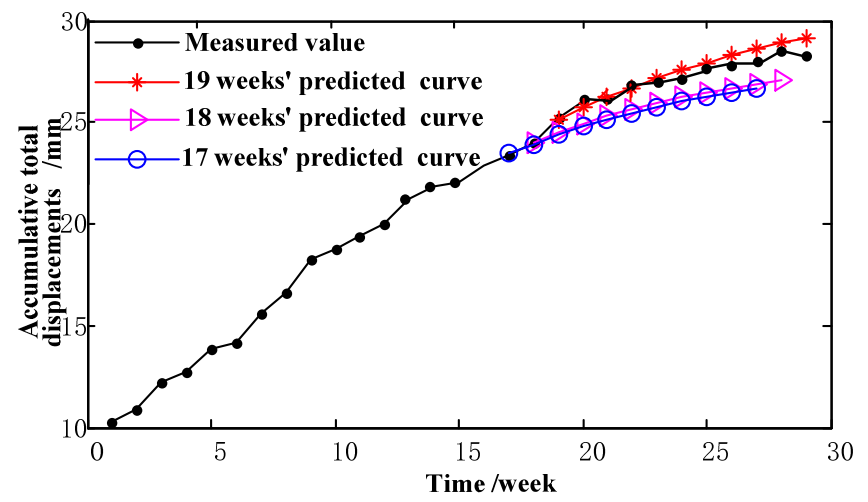

Fig. 3 Comparison of predicted and measured values at 10m depth

The 20th week predicted value is obtained by 17,18 or 19 weeks' Verhulst predicted curve. The ratio of the predicted value and the actual value and posterior error estimator $\mathrm{C}$ are shown in Table 1.

Table 1 The 20th weeks' predicted displacement according to different historical data

\begin{tabular}{cccccc}
\hline Site & $\begin{array}{c}\text { Observatio } \\
\text { n time } \\
/ \text { weeks }\end{array}$ & $\begin{array}{c}\text { Actual } \\
\text { value } \\
/ \mathrm{mm}\end{array}$ & $\begin{array}{c}\text { Predictive } \\
\text { value } \\
/ \mathrm{mm}\end{array}$ & $\begin{array}{c}\text { Predictio } \\
\text { n /actual }\end{array}$ & $\mathrm{C}$ \\
\hline \multirow{3}{*}{ FBG } & 17 & 26.0385 & 24.7908 & 0.9521 & 0.0881 \\
sensor & 18 & 26.0385 & 24.9328 & 0.9575 & 0.0813 \\
& 19 & 26.0385 & 25.7057 & 0.9872 & 0.0729
\end{tabular}

The results show that the prediction accuracy of Verhulst model is high. When we get more historical data, the posterior error estimator $\mathrm{C}$ will be smaller, and the prediction accuracy will be high.

\section{Summary}

The landslide monitoring of transmission corridors is of great significance for the safe operation of power grid. In this paper, wireless sensor network technology and Verhulst model are applied to build the monitoring system of landslide displacement and surface crack, underground water level and rainfall information. Finally, the analyzed accuracy of monitoring system verifies the effectiveness of the system. And the related research has reference value to the engineering application. Meanwhile, for comparison, we also arranged a fiber grating landslide monitoring system to online monitor the slide mass. Related work is already described in another paper.

\section{References}

[1] Cao Yongxing, Chang Ming, Tang Chuan, Li Weile, Ma Guochao. Remote sensing survery and warning for geo-hazards in the Danba-Kangding transmission corridor [J]. Journal of Geological Hazards and Environment Preservation, 2013, 06: 8-15, (in Chinese).

[2] Luo Lei, Tai Nengling, Hu Yan. Design and application of online monitoring system for landslide of transmission lines[J]. East China Electric Power, 2011,07:1097-1101, (in Chinese).

[3] Zhu H H, Ho A N L, Yin J H, et al. An optical fibre monitoring system for evaluating the performance of a soil nailed slope[J]. Smart Structures and Systems, 2012, 9(5): 393-410.

[4] Liang Shan, Hu Ying, Wang Kezhi, et al.. Design of an early-warning system based on wireless sensor network for landslide [J]. Chinese Journal of Sensor and Actuators, 2010 23(8): 1184- 1189, (in Chinese).

[5] Xu Feng, Wang Yang, Du Juan, Ye Jiang. Study of displacement prediction model of landslide based on time series analysis [J]. Chinese Journal of Rock Mechanics and Engineering, 2011, 30(4): 746-751, (in Chinese). 
[6] HUANG Xingbo, LUO Bing, LIU Cunxiao. Designation of wireless acceleration sensor network node using ZigBee chip[J]. High Voltage Engineering, 2010,08:1962-1969.

[7] Deng Julong. Grey control system(2nd Edition)[M]. Huazhong University of Science and Technology Press, 1997, (in Chinese).

[8] Liu Sifeng. Grey systems: theory and applications[M]. Science Press,2008, (in Chinese). 